\title{
Decision Support System for Agriculture Industry using Crowd Sourced Predictive Analytics
}

\author{
Remya S, Dr.R.Sasikala \\ Research Scholar, Department of CSE \\ VIT University, Vellore, Tamilnadu.
}

\begin{abstract}
It is really tough to manually examine the raw data. The Datamining strategies are used to detect the applicable information from uncooked data. The data mining algorithms are efficient for retrieving a specific pattern. In Datamining techniques decision trees are the most commonly used methods for predicting the outcome or behavior of a pattern because they can successfully and efficiently visualize the facts. Presently several decision tree algorithms are advanced for predictive analysis. Right here we gathered a dataset for rubberized mattress, from coir board CCRI, and applied the several decision tree algorithms on the data set and as compared every one. Every set of rules gives a completely unique choice tree from the input statistics. This paper focuses in particular on the Fuzzy c4.5 set of rules and compares one-of-a-kind choice tree algorithms for predictive analysis. Here by using predictive analytics, a decision can be made for each rubberized firms.
\end{abstract}

Keywords-Predictive analytics; coir fiber; fuzzy-C4.5;
crowdsourcing

\section{INTRODUCTION}

Agriculture is a department of technology within the exercise of farming, soil cultivation for growing of vegetation and breeding of animals to afford our primary necessities such as food, medicines, clothes, shelter and the other products. The Indian coir enterprise accomplishes an essential role in the economy of the foremost coconut growing states such as Kerala and Tamil Nadu. Coconut husk is the basic raw material for coir products. At least 50 per cent of the available coir husk is used to produce coir products and the rest is used as fuel in rural areas. Subsequently, coir industry can be grown up [1]. Numerous development programs are also undertaken by the Government authorities for the improvement in quality and production of coir industry. These efforts widen the export markets for coir and coir products. Practically, it's far not possible to accumulate all of the husks for coir production and to achieve most utilization. However, evaluation has been done on the availability of husk for manufacturing, coir manufacturing capacity, actual manufacturing of coir and the capacity utilization globally. Here the goal is to advise a predictive evaluation system with the assist of crowdsourcing [2]

Crowdsourcing is an online tool or model used for solving a problem with the aid of, shared intelligence of interacted communities for precise purposes. The predictive analysis can predict the trends in future and behavior, can understand the outcomes and thereby improving the performance in the industry. It can also help to drive the strategic decision making. The analysis suggests that management authorities can analyzes the husk availability, utilization of husk, coir production, percentage share of the states to coir production and the production potential in India. A comparative analysis of India's coir production with the other countries can also be done with the help of this predictive analysis. Here by using a crowd sourcing algorithm it is possible to predict the international business of coir in South India with the other parts of the country and outside India. This can analyze the expectation of the clients in the areas regarding Ayurveda, Textiles and Agriculture with coir industry[3]. Thus the main objective is to make a better policy development, better decision-making, and thus lead to a sustainable growth in the coir industry for better future.

Indian coir production also has now not unfolded along all the states because of diverse motives together with loss of natural retting facilities, skilled labor and low cost technology. a preceding analysis on the husk availability, utilization of husk, coir production are accomplished and it exhibits that only a small percentage of the coconut husk produced in India is being utilized for coir manufacturing and the remaining major part unutilized. Efforts are being made by means of the coir board to improve the utilization of husks; however they do not be successful due to the absence of natural retting facilities in lots of locations.

The production of value added and innovative products helps to satisfy the global demand and by growing the boom of Kerala's traditional industry products in coir industry [4]. Therefore the success and future development of coir industry in South India particularly relies upon at the ability and the efficiency of the industry to discover the export markets of the coir products. Coconut husk is the primary raw material for the coir industry and the coir manufacturing concentrate mainly in the areas where it is more available. Even though India has a long coastline growing coconut palms; coir industry is concentrated in Kerala. Kerala is the traditional home of Indian coir industry and ranked as the first in coconut production and in coir production and in coir manufacturing and the increase may be in our arms.

\section{INTERNATIONAL TRADE OF COIR}

Global trade is the trade of capital, items, and services throughout international borders or territories. In maximum international locations, such alternate represents a substantial share of gross domestic product(Amarnath \& Brindha, n.d.).

Development and automation of advanced technologies in this superior era, inclusive of transportation, globalization, 
multinational organizations, and outsourcing are all having a primary impact on the international trade system. Increasing worldwide alternate is vital to the continuance of globalization.

India and Sri Lanka are the two top manufacturers of coconut fiber within the international wide. They account for approximately ninety $\%$ of global manufacturing of coir fiber. Sri Lanka was the most important exporter of various fibers inside the international while India exports value added coir fiber merchandise including yarn, mats and rugs. Now a days the request for coir fiber products and the Medicinal, Ayurveda, fabric and Agricultural properties of coconut and coir are growing within the world wide especially in China, Malaysia and Germany[5].However there are such a lot of challenges for the coir industry to expand the markets and get into sustainable.

Small scale industries play a dynamic role in exploiting the resources and giving employability. Indian coir industry is one among that and each unit requires upto 15 works per day and having cost about Rs 5 lakhs in average. At present coconut fiber and ropes are plentiful in India and it has a significant request in the global market. We can establish the coir industry by considering the choice of the market in assist with a decision support system. The coir fiber can be utilized in many forms such as coir yarn, mats, mattress, floor coverings, coir pith and geo textiles.

\section{A. The Challenges Include}

- The fiber value is unreliable and the productivity is very low at the refine level, because of the dearth of a worth based pricing system for coir fiber

- Most of the industry participants do no longer diagnose the necessities at the technical level and distribution systems of current and rising markets for natural fiber merchandise due to the lack of information, and also they do no longer have the competitive opportunities for coir products in domestic markets.

- Now a day's markets for coir fiber are declined, due to the competition from different artificial substances and foreign suppliers.

- Local coir mills process only a fraction of the available husks.

- Working conditions and productivity are generally reduced.

So we ought to improve the reliability of product, expand progressive products together with the assist of customers in importing countries.

\section{B. Global Market Context}

- The technical advantage of coir when compared to other natural fibers is due to the high lignin content and its related stiffness.

- Mild degradation and better flexibility are the properties of coir fibers as compared to other different natural fibers which are used for upholstery works , erosion control products and other applications
Value-added products such as Tawashi brushes, floor coverings and high end twine can have increase or hold the global marketplace volume of coir products. One of the coir product rubberized mattress is discussed here for making coir industry a good challenge. The coir mattress is made by combining the high density of rubberized coir with the core. It is shielded by the jacquard fabric to give a perfect look and feel to the mattress. The rubberized coir mattress is made by using natural fibers such as coconut fiber and unprocessed rubber. It makes the reticulated layers circulate the air properly inside the mattress and maintains an ideal temperature for sleeping [6]. This type of mattress is highly hygroscopic in nature. It has the ability to hold water molecules from the surrounding surface if water or any other liquid splits over it. A mattress has the ability to preserve the moisture and maintain a refreshing impression on the body. Rubberized Coir mattresses are a combination of natural materials like coconut fiber and natural rubber. The combination creates a sheet that provides natural comfort, firm support, allows for air circulation and is non-absorbent[7]. The best quality of coir mattress comes with features such as it has sufficient layers of coir sheets which help it to maintain the firmness and give accurate support to the body. It offers the exact firmness with little cushioning to make it durable. It should be reliable for a long time.

The crowd sourcing based predictive analysis helps to analyses [8]

- Factors limiting market growth and how to improve the growth

- Current market trends and structure

- Expectation of clients

- Up-to-date view of technological improvements

- In depth analysis of business developments

- A precise growth in the technology

- Helps to predict what type of coir product can be developed from a coir samples

\section{TRADE ANALYSIS IN PRODUCTION AND DEVELOPMENT}

\section{A. Coir}

Coir is mined from the outer shell of coconuts surrounding the seed of the coconut palm called Cocos nucifera, and it is the thickest among the commercial natural fibers and more resistive in nature. It is a coarse short fiber. It has a very low decomposition rate and this nature is the added advantage of coir in geotextiles. The average length of coir fiber is $35 \mathrm{~cm}$ and having diameter of 12 to 25 microns units. Usually a coconut is harvested once in 45 days and an average of $10 \mathrm{~kg}$ of coir can be extracted from 1000 coconuts. The lignin component found in the coir makes this one resilient. But it is less flexible than cotton and so unsuitable for dyeing. The tensile strength of coir is less when compared to other natural fibers, but its good resistive nature to micro bial actions keeps it more suitable for agricultural purposes [5]. There is no need of chemical treatment. Mainly two types of coir are widely used such as brown fiber and white fiber. The brown fiber is 
extracted from matured coconuts and the white fiber is extracted from the immature green coconuts. Mature coir fiber contains more lignin content and less cellulose.

\section{B. Environmental Benefits}

Erosion is the main problem in the environment which affects our health also. Coir can be used to overcome erosion problems. Coir geotextiles has the capability to preserve moisture naturally and it protects from the sun radiation .Unlike other geo-synthetic material, the coir fiber provides better soil support up to 4 years

\section{Uses of Coir}

Traditionally coir is extracted from the coconut after the retting process of several months, but now days it is mechanized. There is an increased use of coconut husk de fibering machines. White coir is mainly used in the manufacturing of fishing nets. Brown coir is stronger than white coir and is used for the applications of sacking, doormats, insulation panels, mattresses.

\section{Applications of Coconut Coir}

Upholstery mattresses: Coir is a lot of broadly familiarized in upholstery industry and it is an acceptable interim for synthetic rubber. It can as well be get used to as an aggregate with natural rubber and is used for cushioning and other mattresses [9]

There are several reasons for using coir mattresses. But go head on trying coir mattresses based on your usages and expectations

- Hygroscopic quality: Coir mattresses have the ability to provide refreshing sleeps and it is very comfortable. It can easily absorb moisture.

- Perfect ventilation: They provide maximum air flow in and out the mattresses and that keeps it cool. Thus can enjoy sleep better.

- Added support: The coir mattresses are made with natural fiber only and they are very springy in nature and provide support for the whole body. This can minimize back pain also and aligns the spinal code accordingly

- They are recommended for people with allergies: They do not have any dust and so very much useful for allergic

- Cooling sensation: Its moisturizing absorbed nature allows continuous air flow and thus maintains a smooth temperature to sleep.

- Friendly to the environment: They are 100 percent natural and do not contain any chemicals and so suitable for our health and environment also.
- Great affordability: A good coir mattress can buy with an affordable price ranges in 600 to 1000 dollars .It is ideal for children ,adults and elder people

- They are slightly durable: They can be used for a long period of time and also durable in nature.

- Require no maintenance: No maintenance can be required for coir mattresses unlike other spring or foam mattresses.

At present the coir industry is highly industrialized in India and Sri Lanka only. However it is highly economic in Brazil, Indonesia, and Philippines etc. It is a small scale industry in India and people use local mills for extracting the fiber. Annually around 650000 tons of coir is producing globally, mainly in India and Sri Lanka. They are the main exporters in the coir industry. About 80 percent of the coir produced is carry across as raw fiber and remaining are in the form of yarn, rugs and mats.

India has made a wonderful effort to promote the coir industry including the national and international coir festivals and exhibitions. This effort supports our markets in the coir industry and we can meet the demand. Research and development efforts are also contributed to this area particularly in geo textiles and other new applications. Thus we can promise our prospects in the coir industry. Coconut grown in more than 90 countries in the world and that's why we can grow internationally through coir business [10].

The main production is done by the small holders and so the production of fiber is scattered at small volumes. Integrated farm level processing is a solution this problem and can facilitate greater availability of technology for the dehusking and fiber extraction. Many of the coconut growing countries are not utilizing the husk for making value added products. So India can grow by more concentrating into it and thus provide better employment. Thus we can increase the income of coconut farmers and thereby reducing the poverty also. Improved production with increased qualities and quantities in coir industry must be one of our ultimate aims to grow India faster.

\section{E. Actions taken for improving global markets}

- An international based forum can promote the development section of the coir products, marketing section. It can improve the quality. It can direct the correct way of production and will help to prevent unhealthy competitions. Thus we can improve the business intelligence through this forum

- Innovation can be promoted by getting close to the customers

- Assess Prospects and Needs in Selected Markets

- Concentrate on more Erosion Control Products 


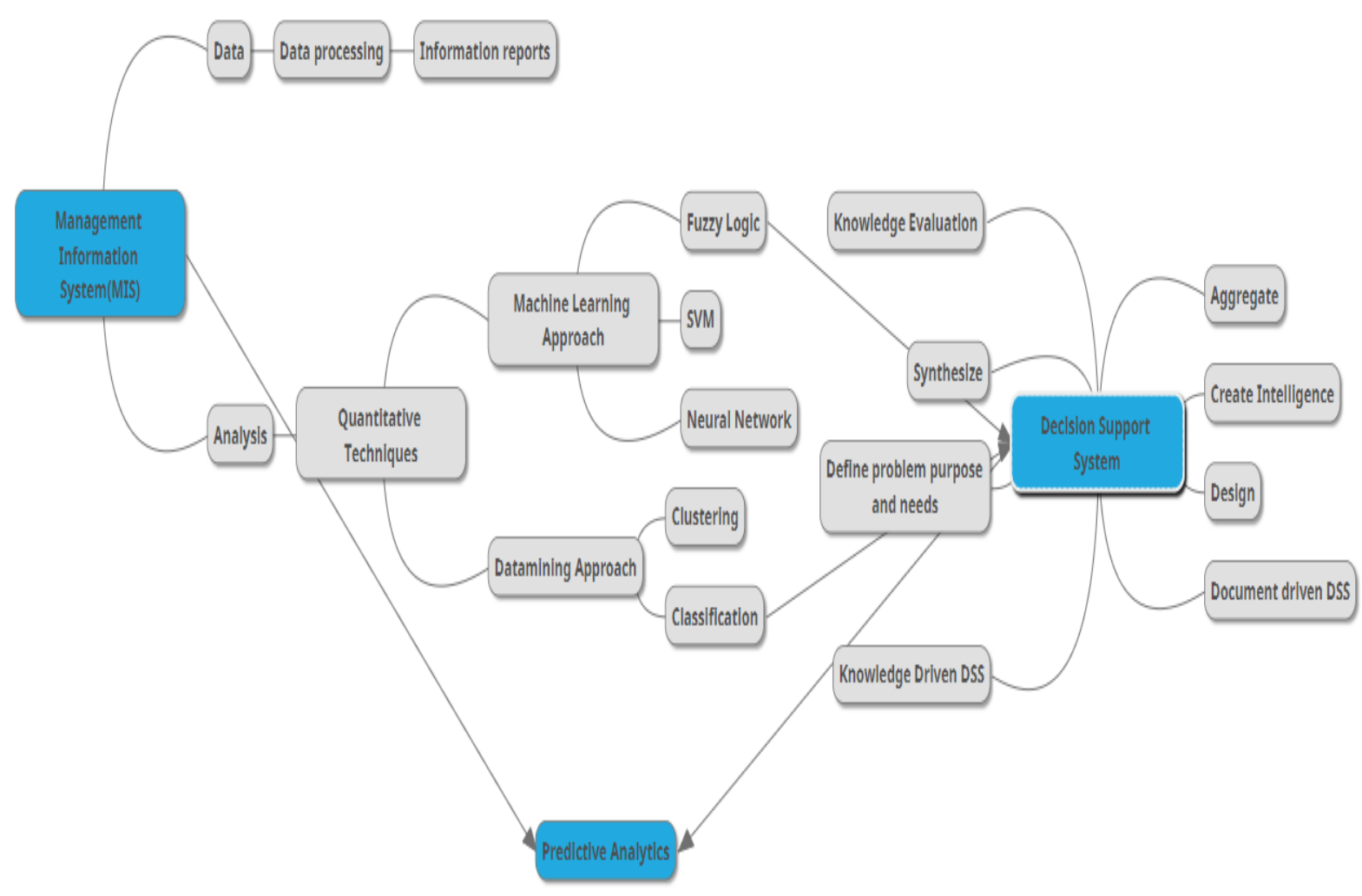

Fig. 1. Work flow of Predictive Analytics

\section{DECISION SUPPORT SYSTEM (DSS)}

Decision support system is used for making decisions in ambiguous and uncertain conditions. Even though many techniques are available for predictive analysis, decision tree is the commonly used system for making decisions in a predicted manner. Decision Support System uses a machine learning algorithm for making decisions [11]. It provides a solution for non-structured problems. Several decision making algorithms are there such as ID3, CART, and C4.5. Here C4.5 algorithm is used for the decision making to establish the coir industry .Here the prediction is performed based on the classification label. In decision tree based method, the training data is categorized into different groups according to the classification label. Here the prediction is performed by using a top down approach known as fuzzy C4.5 algorithm. Statistical classification algorithm is used in this hybrid approach.

A decision support system (DSS) is an automated computerized statistics system used to aid in making decisions in a commercial enterprise or in business. A DSS lets users to examine big piles of data and assemble records that may be used to remedy issues and make better decisions.

The advantages of decision assist structures encompass greater informed choice making, well timed problem-fixing and advanced efficiency for coping with troubles with unexpectedly changing variables.
Decision making process is mostly based on the interactive decision support system with hierarchical structures. It can be categorized into two such as document driven DSS and Knowledge driven DSS. The document driven DSS manages retrieves and manipulate the unstructured information in a variety of electronic formats whereas the knowledge driven system provides specific problem solving expertise stored as facts, rules and procedures. The basic building blocks of DSS consist of the following units such as data bases, query, model creation and execution and statistics and forecasting. Here we combine the two decision support system such as machine learning approach and data mining approach.

Fig.1 indicates the working flow of the proposed predictive analytics. A database system acts as a bank for the decision support system. It fills the information in to the bank and stores the large amount of information that is relevant to the class for the Decision Support System. It provides a logical data structure that has been outlined rather than physical data structures and the user can interact with. The database should be capable of providing information to the user regarding the type of the available data and how to access the data.

We were provided with a training dataset consisting of information about rubberized coir mattress. This data was in the form of a CSV or spreadsheet and had details such as density, IHI, VariAging,flexing,compset aged, compset unaged, $\mathrm{pH}$ value, chloride content and sulphate content. For 
simplicity of performing data mining tasks, the information was filled into a MySQL database.

\section{DATA PREPROCESSING AND QUALITY ISSUES}

Formerly we consumed details; we then segmented the training dataset further, considering numerous viable splitting attributes, i.e. the attributes which could have a better impact at the performance. Over a time of 4 many years the commercial enterprise recorded an extensive alternate in best viewpoints.

Rubberized Coir is an organic product. Coconut fiber is the important and basic raw material that going into the manufacturing process of rubberized coir. In that capacity, this item is bio-degradable as well as ecofriendly. This is the primary factor to support its, particularly when contrasted with its competitors such as PVC and U Foam and other synthetic products. In the present day when condition and environmental conditions are the top most in each perceiving individual's mind. This fact increases its production and propagates it everywhere.

1) The raw material of rubberized mattress is a byeproduct from coconut husk. It is discarded as a waste and also can be used as a material for door mats and floor coverings. Thus the use of rubberized coir is actually boosted as a utility product by which our body can rest and recline. In view of this the price for the raw fiber is increased substantially and an innovative technology has started the production of the rubberized coir products. This will become a benefit to the poor farmers.

2) There are a lot of troubles like excessive cost of the transportation of the raw substances and the coir merchandise throughout the international locations and nation. Additionally the enterprise face several issues within the maintenance of the in- house power plant because if the production as soon as commenced it cannot be stopped in among as the industry prospers moderately well

3) Our present efforts in the Microbiological and chemical Research \& development area need to be focused to accomplish it lighter and adaptable to accomplish it complete absorptive or insulating, and to accomplish fire resistant. All R \& D efforts desire abundant monetary inputs and the industry looks advanced and quickly to Coir Board for their assistance and guidance[12].

\section{PROBLEM STATEMENT}

Generally, to establish an industry in a village, generally we need to consider several parameters such as the availability of raw material, power consumed by the industry, the water required for the processing. Out of these the availability and the quality of the raw material is the very important factor. There are several choices for identifying these requirements. One is the entrepreneur has to gather all the details about these parameters and has to visit all the villages. But it is time consuming and cost effective. He has to take few opinions from the domain experts and it may lead to confusion for making a decision or lead to a false decision.

\section{PROPOSED SYSTEM}

The existing system can be made better by replacing the domain experts. The total time taken can also be reduced by the industrialist by gathering and analyzing the records. It replaces the expert by means of decision support system. The decision support system deal with the selection of the raw material in view of the numerous attributes(Jayasekara \& Amarasinghe, 2010). Additionally it makes which sort of the raw material is suitable for which kind of product. This decision is primarily based on $\mathrm{C} 4.5$ algorithm. The $\mathrm{C} 4.5$ algorithm can build a knowledge level from the industry facts bases and might proceed for the decision making. In fuzzy C4.5 algorithm15], at each node of the decision tree, one of the attribute which is the most effective one of the data set is chosen for splitting it into samples S. These samples are classified into one class or another based on the splitting condition. The splitting condition is based on the information gain of the attribute. This attribute has the highest information gain and that is considered as the criteria for making decisions [13]. Thus we can standardize the data. This process continues up to get the final class choice.

The data base contains information about the parameters of the raw material such as density, IHI, VariAging, flexing, compset aged, compset unaged, $\mathrm{pH}$ value, chloride content and sulphate content. By using FuzzyC4.5 algorithm we can predict which type of the raw material is suitable for which type of the rubberized mattress. This decision support system is a classification and prediction technique and has been applied to the training data set to build a suitable and accurate knowledge base.

While the industrialist needs a selection, at first he need to fill the input form, that is provided by the system. The Decision Support System tests the input data based on knowledge base and generates class label for that entry. Primarily based on that class label, it offers the output to industrialist as suitable or no longer appropriate

\section{A. C4.5 Algorithm}

C4.5 algorithm is used for prediction and the main working is based on the decision tree approach. Branch nodes and leaf nodes are the main concern in a decision tree approach. The branches in the tree represent the attribute choice and the class label is the leaf node and it makes a decision. The action can be start from the root node and the algorithm is applied recursively on each node for constructing the decision tree. By analyzing each branch we will get the idea of the scenario and the output. This is the basic idea of the $\mathrm{C} 4.5$ algorithm. It is a top down and greedy approach and can done a search through the given set of data and can make a classification. For classifying and predicting the class labels a statistical property called information gain is used here[14].

Decision trees are supervised learning method and the aim is to divide the data set into homogeneous groups in terms of the class label and the splitting attributes. The decision is done from root to the leaf.

\section{B. Basic Terms}

The C4.5 algorithm defines the amount of information provided and is known as information gain. For calculating the 
gain first we have to find out the entropy. The entropy and the information gain can be calculated as[15]

Entropy, $P i=\sum_{i=1}^{n}-P i * \log (P i)$

Information gain $(I)=P i-\sum_{k=1}^{n}-P k * \log (P k)$

Where Pi is the set of all possible values for the Attribute A. This information gain is used for ranking the attributes in the given data set and has to build the decision tree based on this ranking.

\section{RESULTS AND DISCUSSION}

\section{A. Fuzzy C4.5 Algorithm}

In Fuzzy C4.5 algorithm, it selects the attribute to be tested based on the information gain which is designed by the likelihood of membership values for statistics in a node. The basic steps to generate a fuzzy decision tree are described here:

1) Make a node which represents the root of the tree and is having the fuzzy membership value as 1 for all training data.

2) The leaf node has to be created iteratively if the element which represents data in the fuzzy set fulfills any of the subsequent conditions:

a) Set a given threshold value and the data set having the number of is less than a given threshold. b) The percentage of objects which represents the data set having a value greater than or equal to the given threshold.

c) If there are no other attributes are presented for classification.

3) The leaf node have to be assigned a name either the name which represents the class or the class names with value of the membership.

4) If the node does not satisfy any of the above conditions then do the following:

a) For all attributes, calculate the information gain; select the attribute that has greatest information gain as the test attribute.

b) Divide the fuzzy data set at the node into fuzzy subsets using the test attribute selected in a, with the membership value of an object in a subset set to the product of the membership value in parent node dataset and the value of the selected attribute fuzzy term in the parent node dataset.

c) For each of the subsets, generate new node with the branch labeled with the fuzzy term of the selected attribute.

5) Recursively repeats the steps from 2 for newly generated node.

The flowchart of the fuzzy-c4.5 algorithm is shown in fig. 2

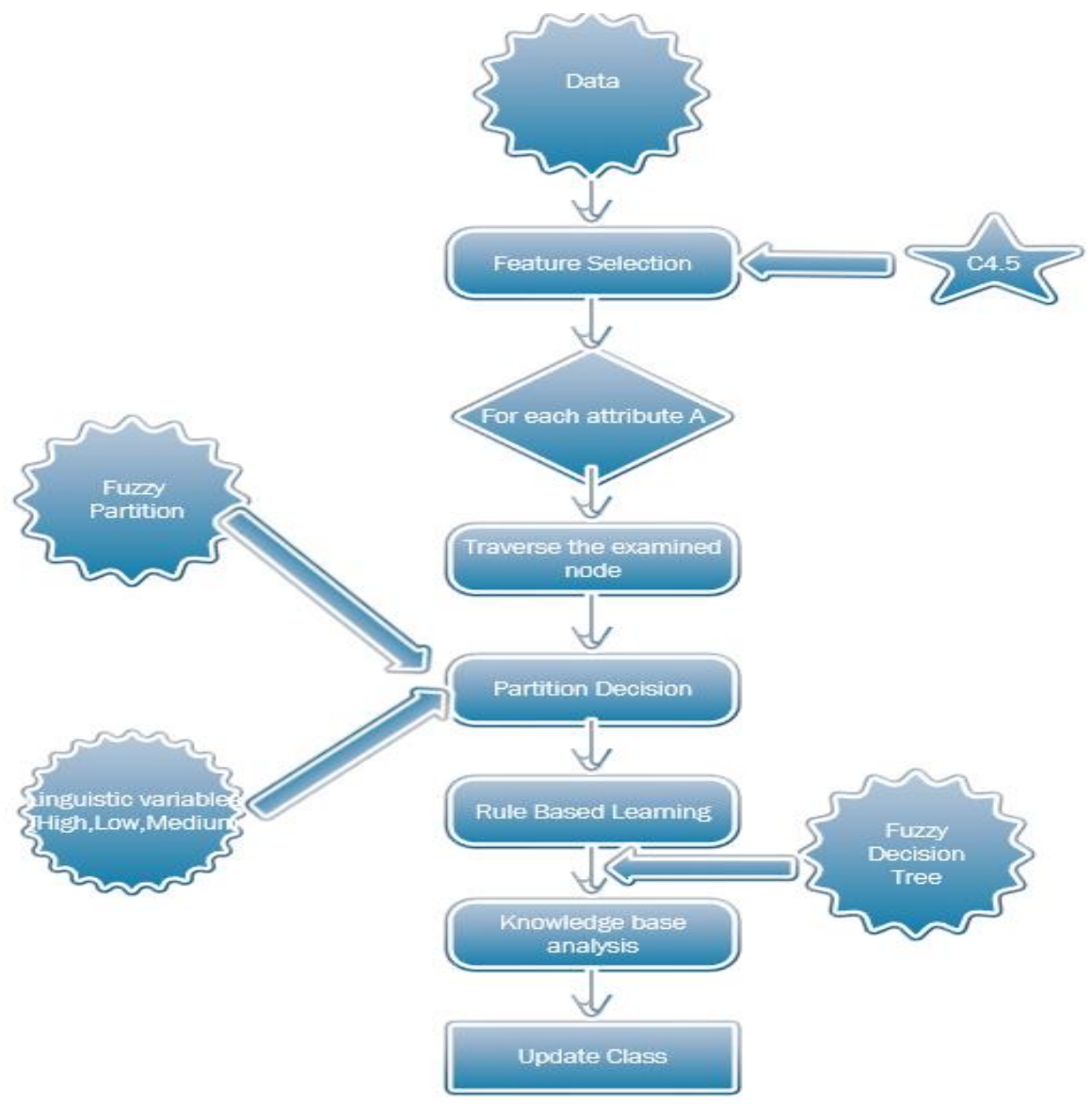

Fig. 2. Flow chart for the FuzzyC4.5 


\section{B. Comparison with Several Algorithms}

Accuracy: "By the term 'accuracy', we mean the degree of compliance with the standard measurement, i.e. to which extent the actual measurement is close to the standard one". Here the Table 1 shows the overview of the decision tree algorithms ID3,C4.5 and Fuzzy-C4.5. The Table 2 presents a performance comparison of Fuzzy-C4.5 and Other algorithms in terms of accuracy with the data set.

TABLE I. OVERVIEW OF DECISION TREE ALGORITHMS

\begin{tabular}{|c|c|c|c|c|c|}
\hline 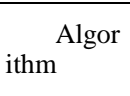 & $\begin{array}{c}\text { Splittin } \\
\text { g Criteria }\end{array}$ & $\begin{array}{l}\text { Attrib } \\
\text { ute Type }\end{array}$ & $\begin{array}{l}\quad \text { Pr } \\
\text { uning } \\
\text { method }\end{array}$ & \begin{tabular}{l}
\multicolumn{1}{c}{ Mi } \\
ssing \\
Values
\end{tabular} & $\begin{array}{r}\text { Outlie } \\
\mathrm{r} \text { detection }\end{array}$ \\
\hline ID3 & $\begin{array}{l}\text { Informa } \\
\text { tion Gain }\end{array}$ & $\begin{array}{l}\quad \text { Handl } \\
\text { es } \\
\text { categorical } \\
\text { value only }\end{array}$ & $\begin{array}{r}\text { No } \\
\text { pruning }\end{array}$ & \begin{tabular}{l}
\multicolumn{1}{c}{ Do } \\
not \\
handle \\
missing \\
Values
\end{tabular} & $\begin{array}{l}\text { Susce } \\
\text { ptible }\end{array}$ \\
\hline C4.5 & $\begin{array}{l}\text { Gain } \\
\text { Ratio }\end{array}$ & $\begin{array}{l}\quad \text { Handl } \\
\text { es } \\
\text { categorical } \\
\text { value and } \\
\text { numerical } \\
\text { value }\end{array}$ & $\begin{array}{l}\quad \text { Err } \\
\text { or } \\
\text { based } \\
\text { pruning }\end{array}$ & $\begin{array}{l}\quad \text { ha } \\
\text { ndle } \\
\text { missing } \\
\text { Values }\end{array}$ & $\begin{array}{l}\text { Can } \\
\text { handle }\end{array}$ \\
\hline $\mathrm{yC} 45^{\text {Fuzz }}$ & $\begin{array}{l}\text { Membe } \\
\text { rship value }\end{array}$ & $\begin{array}{l}\quad \text { Handl } \\
\text { es } \\
\text { categorical } \\
\text { value and } \\
\text { numerical } \\
\text { value }\end{array}$ & $\begin{array}{l}\quad \text { Co } \\
\text { st } \\
\text { based } \\
\text { pruning }\end{array}$ & $\begin{array}{l}\text { ha } \\
\text { ndle } \\
\text { missing } \\
\text { Values }\end{array}$ & $\begin{array}{l}\text { Can } \\
\text { handle }\end{array}$ \\
\hline
\end{tabular}

TABLE II. PERFORMANCE COMPARISON

\begin{tabular}{|l|c|c|}
\hline Algorithm & $\begin{array}{c}\text { Time taken } \\
\text { to build the } \\
\text { model }\end{array}$ & Accuracy \\
\hline FuzzyC4.5 & $0.02 \mathrm{~s}$ & 96.7224 \\
\hline C4.5 & $0.02 \mathrm{~s}$ & 94.6667 \\
\hline ID3 & $0.02 \mathrm{~s}$ & 93.9128 \\
\hline REPtree(CART) & $0.03 \mathrm{~s}$ & 92.7083 \\
\hline Linear NN search & $0.01 \mathrm{~s}$ & 58.3333 \\
\hline Multilayer Perceptron & $0.27 \mathrm{~s}$ & 79.1667 \\
\hline NaiveBayes & $0.28 \mathrm{~s}$ & 80.2083 \\
\hline
\end{tabular}

In Fuzzy C4.5 Algorithm the classification of the output is we can predict "which type of firm "based on the attributes density, IHI, VariAging, flexing, compset aged, compset unaged, $\mathrm{pH}$ value, chloride content and sulphate content. Here only a sample set of values is shown in the Table 3. The original data set contains 1000 values. The C4.5 algorithm differs in several respects from other prediction algorithms

The primary advantages of FuzzyC4.5 algorithm can be stated as

ID3 algorithm selects the best attribute based on the concept of entropy and information gain for developing the tree. FuzzyC4.5 algorithm acts similar to ID3 but improves a few of ID3 behaviors:
- It can deal with the training dataset with missing values of the attributes

- It could cope with the opposing cost attributes

- It prunes the selection tree virtually after its creation

- It could cope with the attributes with discrete and continuous value sets

- speed of the C4.5 algorithm is considerably quicker as compared with the alternative algorithms.

- The FuzzyC4.5 set of rules offers greatly improved scalability of each decision trees and the rule sets. The scalability is more suitable by means of using multithreading and efficient pruning.

- The FuzzyC4.5 algorithm outfits the classifiers for prediction and thereby advances the accuracy.

\section{IMPLEMENTATION RESULT}

The original dataset used for the testing and implementation result is from the Central Coir Research Institute, Alappuzha. Hence the data set is highly confidential here only a sample data set is provided. The dataset is tested with java platform and got the decision tree as shown in figure 3.

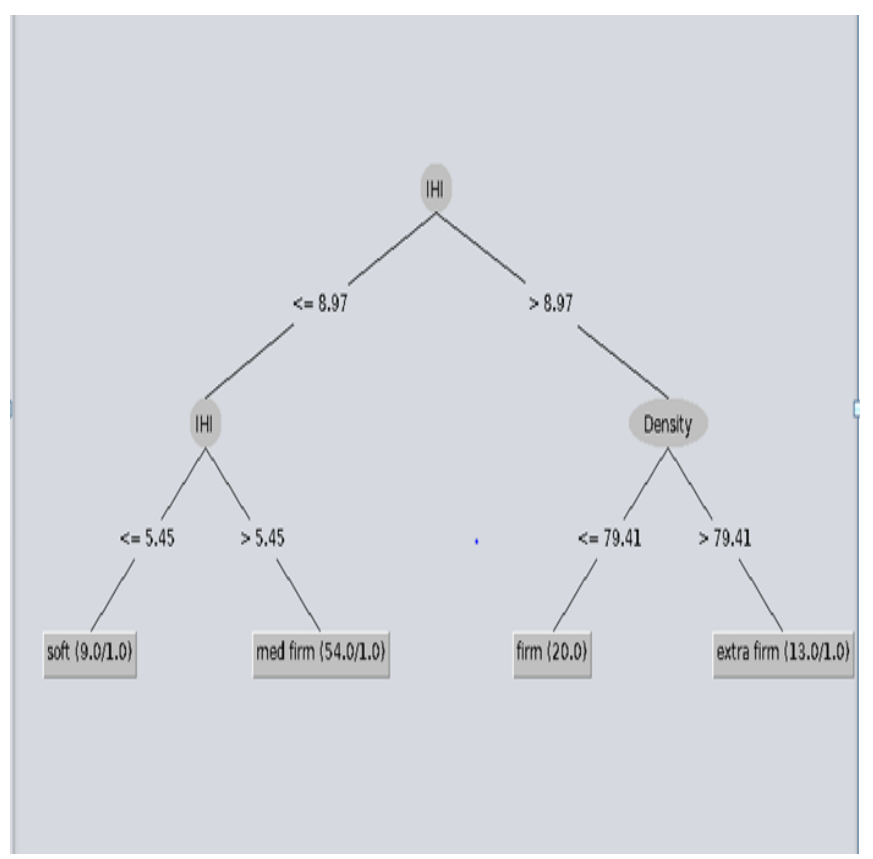

Fig. 3. Decision tree created using Fuzzy C4.5

\section{CONClusion}

At present, decision trees are extensively used in many applications inclusive of medical field, business analysis, diagnosis, cognitive technology, artificial intelligence, engineering and information mining. The class accuracy of selection trees has been a subject of numerous researches. In this paper, we advocate an efficient Fuzzy C4.5 algorithm for data mining. This method provides the performance and the comprehensibility that are crucial to data mining. 
TABLE III. SAmple Dataset VAlues

\begin{tabular}{|c|c|c|c|c|c|}
\hline & nsity & 1 & $\begin{array}{r}V a \\
\text { aging }\end{array}$ & & \\
\hline & $65^{78 .}$ & $55^{10 .}$ & $4.36^{-}$ & -2.75 & 14.44 \\
\hline 2 & $76^{84 .}$ & $588^{12 .}$ & $7.72^{-}$ & -4.69 & 15.84 \\
\hline 3 & $71{ }^{71 .}$ & $63^{10 .}$ & $9.54^{-}$ & -6.22 & 16.67 \\
\hline & $811^{64 .}$ & $\begin{array}{ll} & 7.4 \\
5 & \end{array}$ & $\begin{array}{r}-\overline{-} \\
16.43\end{array}$ & 15 & 17.87 \\
\hline 5 & 2368. & $\begin{array}{ll} & 7.9 \\
9 & \end{array}$ & $6.09^{-}$ & -8.7 & 8.18 \\
\hline & 7177. & $8^{11 .}$ & 6.15 & -6.33 & 13.57 \\
\hline & $75^{94 .}$ & $73^{14 .}$ & $5.52^{-}$ & -4.44 & 7.73 \\
\hline & $53 \quad 68$. & 8.9 & 1.12 & 1.68 & 7.72 \\
\hline & $94 \quad 66$. & $\begin{array}{ll} & 7.2 \\
2 & \end{array}$ & $14.9^{-}$ & -15.27 & 14.36 \\
\hline $\begin{array}{ll} & 1 \\
0 & \end{array}$ & 5268. & 8.7 & 15.49 & 16.36 & 16.47 \\
\hline \begin{tabular}{ll|} 
& 1 \\
1 &
\end{tabular} & $\begin{array}{ll} & 76 . \\
9 & \end{array}$ & 6510. & $3.56^{-}$ & 19.44 & 18.52 \\
\hline 2 & $\begin{array}{ll} & 88 . \\
57 & \end{array}$ & $8^{12 .}$ & $4.51^{-}$ & 13.06 & 19.9 \\
\hline $\begin{array}{ll} & 1 \\
& \end{array}$ & 3968. & $\begin{array}{ll} & 8.6\end{array}$ & $\begin{array}{r}- \\
15.88\end{array}$ & 11.58 & 19.81 \\
\hline $4^{1}$ & 07 68. & $\begin{array}{ll} & 8.6\end{array}$ & $9.64^{-}$ & -1.12 & 19.52 \\
\hline \begin{tabular}{ll|} 
& 1 \\
&
\end{tabular} & 4968. & 8.7 & 15.7 & -1.69 & 12.14 \\
\hline 1 & $75{ }^{48 .}$ & $\begin{array}{ll} & 3.9 \\
7 & \end{array}$ & 18.69 & -15.96 & 15.73 \\
\hline
\end{tabular}

Here we used a data set from the CCRI for the classification and prediction purpose and got $96 \%$ accuracy in the results. In particular, the method permits us to correctly classify patterns of decision boundaries well, that is difficult to do the use of attribute based classification strategies. The rubberized mattresses are classified here based on the attribute values. The experiment outcomes show that our technique is greater efficient in overall performance and clarity of rules in comparison with other techniques which include C4.5. Our initial experiments have proven that the algorithm is strong for many real world applications. Future work is to expand a fuzzy decision tree pruning algorithm to generate greater compact deep learning methods. We also plan for improving the algorithm a good way to manage a large volume of data efficiently, which is often an important requirement to data mining.

\section{REFERENCES}

[1] Dasanayaka, S. W. S. B., \& Sardana, G. D. (2010). Development of SMEs through clusters: a comparative study of India, Pakistan and Sri \begin{tabular}{|l|l|l|l|l|}
\hline \multicolumn{1}{|c|}{ pom } & chlor & sulphate & Grade \\
unaged \% & $\begin{array}{l}\text { H } \\
\text { value }\end{array}$ & $\begin{array}{l}\text { ide } \\
\text { content\% }\end{array}$ & content\% & \\
\hline
\end{tabular}

\begin{tabular}{|c|c|c|c|c|}
\hline 5.56 & 6.4 & 0.08 & 0.04 & Firm \\
\hline 7.14 & 6.4 & 0.07 & 0.09 & extra firm \\
\hline 12.6 & $5^{6.4}$ & 0.02 & 0.02 & Firm \\
\hline
\end{tabular}

\begin{tabular}{|c|c|c|c|c|}
\hline 12.6 & $5^{6.4}$ & 0.02 & 0.02 & Firm \\
\hline 12.5 & 6.5 & 0.08 & 0.04 & med firm \\
\hline
\end{tabular}

\begin{tabular}{|l|r|c|c|c|}
\hline 12.5 & 6.5 & 0.08 & 0.04 & med firm \\
\hline 4.55 & 6.5 & 0.02 & 0.02 & med firm \\
\hline
\end{tabular}

\begin{tabular}{|c|c|c|c|c|}
\hline 5.5 & 6.5 & 0.01 & 0.01 & Firm \\
\hline 5.84 & $\begin{array}{ll} & 6.4 \\
5\end{array}$ & 0.08 & 0.04 & extra firm \\
\hline
\end{tabular}

\begin{tabular}{|c|r|c|c|c|}
\hline 2.85 & 6.5 & 0.08 & 0.04 & med firm \\
\hline 10.91 & 6.5 & 0.1 & Nil & med firm \\
\hline
\end{tabular}

\begin{tabular}{|c|c|c|c|c|}
\hline 13.52 & 6.5 & 0.1 & Nil & med firm \\
\hline 10.28 & $\begin{array}{ll} & 6.4 \\
\end{array}$ & 0.08 & 0.01 & Firm \\
\hline
\end{tabular}

\begin{tabular}{|c|c|c|c|c|}
\hline 9.81 & 6.5 & 0.04 & 0.02 & extra firm \\
\hline 14.15 & $\begin{array}{ll} & 6.5 \\
3\end{array}$ & 0.18 & 0.08 & med firm \\
\hline 10.9 & 6.4 & 0.16 & 0.095 & med firm \\
\hline 9.43 & 6.2 & 0.22 & 0.1 & med firm \\
\hline 13.37 & 5.9 & 0.25 & 0.08 & Soft \\
\hline
\end{tabular}

Lanka. World Review of Entrepreneurship, Management and Sustainable Development, 6(1-2), 50-70

[2] Allahbakhsh, M., Benatallah, B., Ignjatovic, A., Motahari-Nezhad, H. R., Bertino, E., \& Dustdar, S. (2013). Quality control in crowdsourcing systems: Issues and directions. IEEE Internet Computing, 17(2), 76-81.

[3] Turban, E., Sharda, R., \& Delen, D. (2011). Decision support and business intelligence systems. Pearson Education India

[4] Thomas, S., Woh, Y., Wang, R., \& Lim, K. (2017). ScienceDirect ScienceDirect Probing the hydrophilicity of coir fibres : analysis of the mechanical properties of single coir fibres. Procedia Engineering, 200, 206-212. https://doi.org/10.1016/j.proeng.2017.07.030

[5] Amarnath, J. S., \& Brindha, M. (n.d.). An Investment and Export Analysis of Coir Enterprise in Tamil Nadu, India.

[6] Dasanayaka, S., Sardana, D. G., \& others. (2015). Development of Small and Medium Enterprises through Clusters and Networking: A Comparative Study of India, Pakistan and Sri Lanka. International Journal of Economics and Business Administration, 3(2), 84-108.

[7] Fernandez, C. (2003). STRATEGIC ALLIANCE FOR THE DEVELOPMENT OF COIR INDUSTRY IN THE APCC COUNTRIES AND DEMAND PROSPECTS FOR COIR PRODUCTS IN ECOFRIENDLY APPLICATIONS.

[8] Abu-halaweh, N. M., \& Harrison, R. W. (2009). Practical Fuzzy Decision Trees 
[9] Waller, M. A., \& Fawcett, S. E. (2013). Data science, predictive analytics, and big data: A revolution that will transform supply chain design and management. Journal of Business Logistics, 34(2), 77-84. https://doi.org/10.1111/jbl.12010

[10] Wilson, C. (2007). Flow resistance models for flexible submerged vegetation. Journal of Hydrology, 342(3-4), 213-222

[11] Sierra-Pérez, J., Boschmonart-Rives, J., \& Gabarrell, X. (2015). Production and trade analysis in the Iberian cork sector: Economic characterization of a forest industry. Resources, Conservation and Recycling, 98, 55-66. https://doi.org/10.1016/j.resconrec.2015.02.011
[12] Turban, E., Sharda, R., \& Delen, D. (2011). Decision support and business intelligence systems. Pearson Education India

[13] Prasad, M. (1996). Physical, chemical and biological properties of coir dust. In International Symposium Growing Media and Plant Nutrition in Horticulture 450 (pp. 21-30)

[14] Jayasekara, C., \& Amarasinghe, N. (2010). Coir--Coconut Cultivation, Extraction and Processing of Coir. Industrial Applications of Natural Fibres: Structure, Properties and Technical Applications, 197-217.

[15] Kim, M. W., Lee, J. G., \& Min, C. (1999). Efficient Fuzzy Rule Generation Based on Fuzzy Decision Tree for Data Mining 